\title{
Therapeutic landscapes and First Nations peoples: an exploration of culture, health and place
}

\author{
Kathleen Wilson \\ School of Geography and Geology, McMaster University, 1280 Main Street West, Hamilton, Ontario, Canada L8S 4K1
}

Received 21 May 2001; received in revised form 1 October 2001; accepted 15 March 2002

\begin{abstract}
This paper contributes to an expanding body of research within Health Geography that focuses on the role of therapeutic landscapes in shaping health. Therapeutic landscapes demonstrate the importance of places for maintaining physical, emotional, mental and spiritual health. Meanings of place and the relationship between place and health have culturally specific dimensions, yet these tend to be overlooked especially with respect to First Nations peoples. This paper broadens the analysis of therapeutic landscapes by exploring their culturally specific dimensions in the context of the everyday lives of 'Anishinabek' and thus contributes to a better understanding of First Nations peoples.

First Nations peoples contend that the relationship they have with the land shapes the cultural, spiritual, emotional, physical and social lives of individuals and communities. While geographic research has explored First Nations peoples health, few studies have attempted to explore the influence of cultural beliefs and values on health-let alone the intricate link between the land and health. This paper presents the results of 17 in-depth interviews conducted with Anishinabek (Ojibway and Odawa) living in one First Nations community in northern Ontario, Canada.

The findings from the interviews demonstrate that culture is an important component of the link between health and place in everyday life. Incorporating First Nations peoples' perspectives of health and place reveals that the current conceptualizations of health and place within the Geography of Health literature are only partial.
\end{abstract}

(C) 2003 Elsevier Science Ltd. All rights reserved.

Keywords: Therapeutic landscapes; Culture; First Nations peoples

\section{Introduction}

This paper contributes to an expanding body of research within Health Geography that focuses on the role of therapeutic landscapes in shaping health. In particular, it examines the importance of the land for the health of First Nations peoples. ${ }^{1}$ By exploring the complex link between place (the land) and health, this paper demonstrates that the current conceptualization

\footnotetext{
${ }^{1}$ When using the term Aboriginal I am referring to the descendants of the original inhabitants of Canada, as defined by the Constitution Act 1982; Indians, Inuit and Métis. Many 'Indians' prefer the terms First Nations when referring to themselves as a collective group. Therefore I use the term First Nations when referring to this segment of the Aboriginal population.
}

of therapeutic landscapes as primarily physical and/or symbolic locations of healing is limited in scope. Most papers published on therapeutic landscapes focus on extraordinary events in peoples lives - going to spas or shrines. What distinguishes this research is that it places much more emphasis on the social and spiritual aspects of place but more importantly, it focuses on the everyday lives and geographies of First Nations peoples. The findings from in-depth interviews show that the land, as place, is an integral part of First Nations peoples' identity and health. The land does not just represent a physical space but rather, represents the interconnected physical, symbolic, spiritual and social aspects of First Nations cultures.

The first section of this paper briefly discusses the current literature on therapeutic landscapes, highlighting the need for different (non-'Western') 
conceptualizations of place by incorporating indigenous perspectives on health and place and the importance of therapeutic landscapes in people's everyday lives. The second section outlines the methods used in this study, as well as concerns regarding methodology. In the third section, the results of the research are presented. The results illustrate the meaning of the land for First Nations peoples, how they relate to it and how it contributes to health. In the final two sections of this paper, the key findings of this research are summarized and future areas of research are discussed.

\section{Revisiting therapeutic landscapes}

Recent research conducted within the Geography of Health has been instrumental in promoting and emphasizing the need for health research that focuses on place as a zone of experience and meaning (see Abel and Kearns, 1991; Gesler, 1991; Kearns and Gesler, 1999; Kearns and Joseph, 1993). Situating himself between the new cultural geography and health geography, Gesler (1991) first introduced geographers to the term 'therapeutic landscapes' in his book The Cultural Geography of Health Care. Gesler (1993, p. 171) defined therapeutic landscapes as places with "an enduring reputation for achieving physical, mental, and spiritual healing" and argued that by incorporating theory from cultural geography such as sense of place and symbolic landscapes, health geographers could begin to examine 'locations of healing' as symbolic systems. This, he felt, would move health geography beyond mere locational analyses of health care delivery to more in-depth examinations that explored places as sites of meaning. Gesler argued this was necessary for recognizing that societies, through ideologies and the use of symbols, create therapeutic landscapes of healing.

Since Gesler first introduced the concept of therapeutic landscapes in 1991, many Health Geographers have taken on the task of applying this new body of theory to our understandings of the interconnections between place, identity and health. For example, utilizing notions of sense of place and attachment to home, Williams (1999) explored the factors relating to the placeidentities of home care nurses working in a medically under-serviced region in Sault Ste. Marie, Ontario, Canada.

Research has also demonstrated the symbolic structures embedded within therapeutic landscapes. For example, Gesler (1991) identifies the symbolic importance of physicians' white coats. He argues that the coats symbolize an array of things to different people (e.g., hope, purity, and colonial oppression). The different landscapes (e.g., hospitals and cities) within which health care is delivered are also of symbolic importance.
As such, healing places symbolize social ideals, values and beliefs.

Geores (1998) takes a historical approach to demonstrate how the meaning and symbolism of the metaphor 'Health $=$ Hot Springs' served to commodify Hot Springs, South Dakota as a therapeutic landscape in the late 18th and early 19th centuries. Her work illustrates how a sacred Native American healing place was commodified and marketed as a healing place for 'white' Americans. Similar to Kearns and Barnett's (1999) research on the importance of marketing for selling health care, Geores research shows how the marketing of nature (e.g., mineral springs and fresh air) as healing sold the metaphor of Hot Springs as a therapeutic place.

The use of therapeutic landscapes within health geography is important because it provides us with an alternative way of viewing the link between health and place. It allows us to shed geometric and locational approaches to space and place (see Jones and Moon, 1993) by embracing more meaningful perspectives that view places as symbolic systems of healing. Using this body of theory, researchers have successfully demonstrated the healing benefits associated with the symbolic and material aspects of particular places such as spas, baths, places of pilgrimage, and hospitals (see Bell, 1999; Geores, 1998; Gesler, 1993, 1996, 1998; Palka, 1999).

While therapeutic landscapes are an informative and innovative area of research, there are two limitations to current research: first, the research overlooks the culturally specific dimensions of the links between health and place; and second, in doing so, the research does not recognize that therapeutic landscapes represent more than just physical or symbolic sites of healing. Each of these issues will be discussed in turn.

Therapeutic landscapes, as a concept, is very much a 'Western' conceptualization that does not allow for the incorporation of 'other' ways of viewing the link between health and place. It focuses on landscapes that are mainly important in western cultures (e.g., spas and baths) yet their healing benefits are presented as holding universal meanings. There has been very little acknowledgement of the cultural specificity of these landscapes and perhaps more importantly much of the research neglects therapeutic landscapes in people's everyday lives.

The complaint that health geographers fail to acknowledge the ethnic and racialized underpinnings of the relationship between health and place is not something new. Rathwell and Phillips (1986), observing a need for 'socially relevant' research, edited a book that centred on health, race and ethnicity. In 1988 Pearson argued the need for a 'feminist anti-racist medical geography' (Pearson, 1988). Three years later Gesler (1991, p. 8) emphasized that health geographers must begin to focus on ethnicity and ethnomedical systems in 
their examinations of health and place. Kearns and Dyck (1995, p. 137) argued that "geographical studies of health and place need to be centred in 'culturally safe' research practice". It is not enough to include others within our research but we must acknowledge diversity, difference and the existence of multiple identities and their role in shaping health. More recently, Rosenberg (1998) argued that health geography has failed in its attempts to develop inclusive geographies of health and place. While Gesler (1991, p. 8) states that the "bridge between what cultural geographers have been doing and what medical geography might be doing has been partially filled", I would argue that there is still much work that needs to be done and that therapeutic landscapes as a concept needs to be broadened if the gap identified by Gesler is to be filled.

A review of recent work conducted by health geographers on therapeutic landscapes reveals that there is little or no reference to ethnicity and/or culture and their role in shaping the link between health and place. ${ }^{2}$ In addition, only three articles explore therapeutic landscapes outside the geographic borders of North America, Europe and New Zealand. They are, Scarpaci's (1999) examination of the development of therapeutic landscapes in post-socialist Havana, Frazier and Scarpaci's (1998) exploration of the confluence of 'landscapes of fear' and therapeutic landscapes within the context of state violence and mental health in Chile, and Madge's (1998) work on the health care system of the Jola of The Gambia, West Africa. Of these, Madge's research is the only one that focuses specifically on cultural beliefs and values in shaping therapeutic landscapes. Her research explores the indigenous medical beliefs and practices of the Jola, documenting the medicinal uses of plants and animals for particular illnesses and ailments, and the use of indigenous medical specialists.

Madge's research is important because she demonstrates that it is not enough to include others within our research. Rather, we also must acknowledge that there are indigenous ways of knowing, which are valid and may challenge and contradict 'Western' perceptions of health and place. Similarly Kearns and Dyck (1995, p. 143) argue for the importance of allowing other conceptualizations of health and place to "transform one's theoretical building blocks as a social scientist". As researchers we must be flexible enough to shed our Western lenses, for it is only when we incorporate other

\footnotetext{
${ }^{2}$ Included in this review were five journal articles with the term 'therapeutic landscapes' in their title/abstract/key words, three papers included in a section entitled 'Therapeutic Landscapes' in the edited collection Putting Health into Place: Landscape, Identity, and Well-Being (Kearns and Gesler, 1999), and ten papers in Williams' (1999) edited collection Therapeutic Landscapes: The Dynamic Between Place and Wellness.
}

ways of seeing that we can begin to see the limitations of our own epistemologies.

Second, much of our understanding of therapeutic landscapes has been limited to the healing properties of physical places that can be mapped, such as, spas, baths, sites of religious pilgrimages, and hospitals (see Bell, 1999; Geores, 1998; Gesler, 1996, 1998; Palka, 1999; Gesler, 1992). As such, research has overlooked the everyday geographies of therapeutic landscapes. We must begin to explore other (non-physical) dimensions of therapeutic landscapes; in particular those that do not exist solely 'on the ground' but are embedded within the belief and value systems of different cultural groups. The relationship between health and place has culturally specific dimensions but these tend to be overlooked, especially with respect to indigenous peoples.

Within the Canadian context, very few geographers have conducted in-depth explorations of the cultural beliefs systems of Aboriginal peoples and how they shape health. This paper marks the beginning of a journey that tries to 'map' a different approach to understanding the importance of therapeutic landscapes. Much of the research on therapeutic landscapes is centred on extraordinary events in people's lives that take place in particular locations, such as, religious pilgrimages or trips to national parks. The approach offered in this paper differs in that it focuses on the everyday lives and geographies of First Nations peoples by exploring the importance of relationships to the land and their role in forming identity and health.

\section{Methods}

To understand the ways in which relationships to the land contribute to the health of First Nations peoples, in-depth interviews were conducted with individuals living on one relatively isolated First Nations' reserve in northern Ontario, Canada. The community is comprised of individuals with Odawa and Ojibway ancestry. Odawa and Ojibway peoples, like many Algonquin peoples, use the term Anishinabek, meaning 'First Peoples', to refer to themselves. ${ }^{3}$ As such, the term Anishinabek is used to refer to the people who participated in this research.

According to community statistics, the reserve has 335 registered band members, 126 of which reside on reserve. The population is relatively young with slightly more than $50 \%$ of the population between the ages of 16 and 45. There is an even distribution of men and women. In terms of social status, unemployment is high with only $25 \%$ of the population of working age being employed

\footnotetext{
${ }^{3}$ More formally, Benton-Banai (1988, p. 3) defines the term as "from whence the male species was lowered". The spelling of this term varies with different dialects.
} 
on either a part-time or full-time basis. The First Nations' band is the main employer with $83 \%$ of the employed working in either the band or the health centre. A handful of individuals work off-reserve for forestry or logging companies.

After having resided in the community for a period of 2 months and establishing what I felt was an appropriate level of trust, I began asking people to participate in my research. Kirby and McKenna (1989) and Johnson (1990) identify a number of factors to take into account when selecting participants for research. They argue for selecting individuals who are: (i) geographically accessible; (ii) willing to participate in the research and share their experiences; and (iii) the degree to which an individual has reflected and thought about the research issues at hand.

While all of these issues are important, there are other factors that are important to take into consideration when conducting research with First Nations peoples. First, colonial policies have served to disrupt and, in some instances, alter the ways in which First Nations peoples relate to the land. There were a handful of individuals in the community who themselves had attended or whose parents had attended residential school. Hence, many individuals grew up in an environment where spiritual beliefs and teachings were suppressed. Some are now undergoing a process of regaining those teachings. Since individuals begin the learning process at different stages in their lives, it did not make sense to choose interviewees based on age. For example, in talking to people I found that some younger individuals knew more about their spirituality than some middle-aged individuals. That is, while I did try to include people who I thought had an intimate knowledge of the land, I was also very open to interviewing anyone who was willing to speak to me. As such, the spirituality of the people I interviewed varied, ranging from what some termed as 'just learning' to others who were very knowledgeable and held important spiritual roles within the community. This brings me to a second important issue in selecting participants - elders.

The term elder in First Nations communities refers to an individual with knowledge of traditional ways and uses this knowledge to teach others (Medicine, 1983; Stiegelbauer, 1996; Waldram, 1993). The knowledge that elders have is gained through life experience. As such, the term tends to be associated with more senior individuals. However as McLeod-Shabogesic (1998) notes, the term also refers to an individual "gifted with the ability to learn more things and be able to pass them on regardless of age". Since elders hold important status within First Nations communities as both teachers and role models I wished to include them in my research. I was fortunate to have been able to interview three elders.

A total of 17 in-depth interviews were conducted during the fall of 1998 and the spring of 1999, fourteen of which were conducted with community members. Nine of the community interviews were with women and five were with men. Initially, I had asked 21 community members to participate but only 15 agreed. The reasons I was given for refusal varied from a 'lack of time' to individuals stating that they did not know enough about their culture and their spirituality to participate in my research. In fact, one woman stated that because of the residential school system and the influence of the church she was neither taught nor was she allowed to practice her traditions.

Of the 17 interviewees, two worked for the community health centre, but were neither physicians nor nurses, one was a traditional healer, one was a medicinal harvester and the remainder had a range of occupations unrelated to either conventional medicine or traditional health practices. There is no prima facie evidence from the interviews that the community health centre employees were biased against traditional health practices or that the traditional healer or medicinal harvester were biased against conventional medicine. In fact, all of the interviewees use both conventional medicine and traditional health practices in their everyday lives.

Most of the interviews took place at the homes or work places of each participant. However, two interviews were conducted at the community health centre and one interview, which lasted an entire day, took place in various outdoor locations within the traditional territory. All of the interviews were conducted in English. The interviews were semi-structured in design and detailed theme areas were identified prior to the interviews. Each interview started with a general statement that asked individuals to describe the land and their relationship to it and then developed from that point forward. Open-ended questions were asked, followed by probes that tried to cover themes.

Each interview was more reflective of a conversation rather than a structured interview session. In fact, the structure of the interview and the questions asked changed with each individual. This style of interviewing was chosen because the literature suggests that direct questioning (e.g., questions requiring 'Yes/No' for answers) is an inappropriate method to use with most First Nations groups. Both the linguistic and medical literatures argue there is a need for ethno-specific communication methods, such as indirect questioning, when conducting research with Aboriginal peoples (see Briggs, 1986; Macaulay et al., 1989; Spielmann, 1998; Valentine, 1995).

\section{Methodological considerations: engaging in research with the 'other'}

Before presenting the results of this research, there is an important methodological consideration that must be addressed. The issue of engaging in research with the 
'other' is at the forefront of discussions in Feminist, Cultural and Post-Colonial studies, with prominent viewpoints coming from among others Spivak (1988), Said (1993), Bhabha (1994), and Hooks (1990). Debates surrounding research with the other have raised some critical questions concerning representation and have stressed the importance of recognizing that all knowledge is partial, situated and socially produced. In conducting and presenting the results from this research, I risk "continuing the imperialist project" (Spivak, 1988, p. 288) of speaking for others.

Throughout this paper, interpretations of the link between Anishinabek health, culture and relationships to the land are presented and this constitutes a form of speaking for others. However, it is not the goal of this paper to uncover universal truths and make grand claims regarding the link between health, culture and place. Nor is it the goal of this paper to present an authoritative account of Anishinabek perspectives on the significance of their relationships to the land and its implications for health. Rather, the goal is to demonstrate that exploring health in the context of Anishinabek culture provides us with an'other' way of viewing place. Incorporating Anishinabek perspectives of place into the analysis of health results in what Spivak (1988) terms the creation of counter-narratives. These counternarratives demonstrate that the current conceptualizations of health and place within the Geography of Health are limited and that more nuanced perspectives of health, culture and place are required. In particular, the paper reveals that for Anishinabek, places are more than just physical and/or symbolic locations. Rather, the land, as place, represents the daily interconnected physical, symbolic, spiritual and social aspects of Anishinabek cultures and it is essential for maintaining the balance necessary for good health.

\section{Examining the interconnections of culture, health and place}

The results are presented in four stages. First, Anishinabek conceptions of health are presented through a discussion of the medicine wheel. In the second stage, the significance of the land as the basis of Anishinabek identity is demonstrated through an exploration of the land in the image of Mother Earth. In the third stage, the paper discusses the ways in which the land contributes to holistic health. Finally, the paper examines the importance of particular landscape features, such as symbols of cultural identity and how they contribute to health.

To understand fully the link between the land and health, it is first necessary to explore Anishinabek conceptions of health. The concept of health in Anishinabek cultures is a complex notion that takes us beyond traditional biomedical models of health. The Ojibway word mno bmaadis, which translates into 'living the good life' encapsulates beliefs in the importance of balance. The concept of health or living the good life is a complex notion and its basic tenets are explained through the medicine wheel. As illustrated in Fig. 1, the medicine wheel is divided into four sections that represent the four directions: Giiwednong (North), Waabnong (East), Zhaawnong (South), and Epngishmok (West).

According to beliefs, all four elements of life, the physical, emotional, mental and spiritual, are represented in the four directions of the medicine wheel. These four elements are intricately woven together and interact to support a strong and healthy person. One of the main teachings of the medicine wheel is that balance between all four elements is essential for maintaining and supporting good health (Bopp et al., 1984; Canada, 1997; Dyck, 1996; RCAP, 1996d). Balance extends beyond the individual realm such that good health and healing also requires that an individual live in harmony with others, their community and the spirit worlds (Malloch, 1989). To be healthy an individual must embark upon a journey that takes them beyond physical health and requires balance between all aspects of life. If one element within the wheel is neglected or receives too much attention then health suffers in all four areas (Malloch, 1989).

Given that all four elements of life are represented in the four directions of the medicine wheel, this research sought to understand the ways in which the land contributes to physical, mental, emotional and spiritual health. The interviews revealed that Mother Earth (the land) supports all four elements of life on a daily basis through what she provides and this in turn supports health. It is by utilizing what the land provides that individuals are able to maintain the balance necessary for health. Before discussing how the land contributes simultaneously to the four elements of life, this paper will first describe the meaning of the land and its importance for identity.

Historically, a relationship with the land has been an important component of First Nations peoples' lives and cultures. Before European contact most First Nations groups in Canada could be described as subsistence cultures with the diet and daily nourishment of these groups provided by the land (Dickason, 1997). In the contemporary context, many First Nations peoples no longer live off the land, as they once did; however, they claim that the land is still an essential component of their culture. The Royal Commission on Aboriginal Peoples in Canada suggests that a common theme among First Nations cultures is a belief in the importance of the land and a life based on stewardship and harmony with the earth (RCAP, 1995). Aboriginal peoples contend that the relationship they have with the 


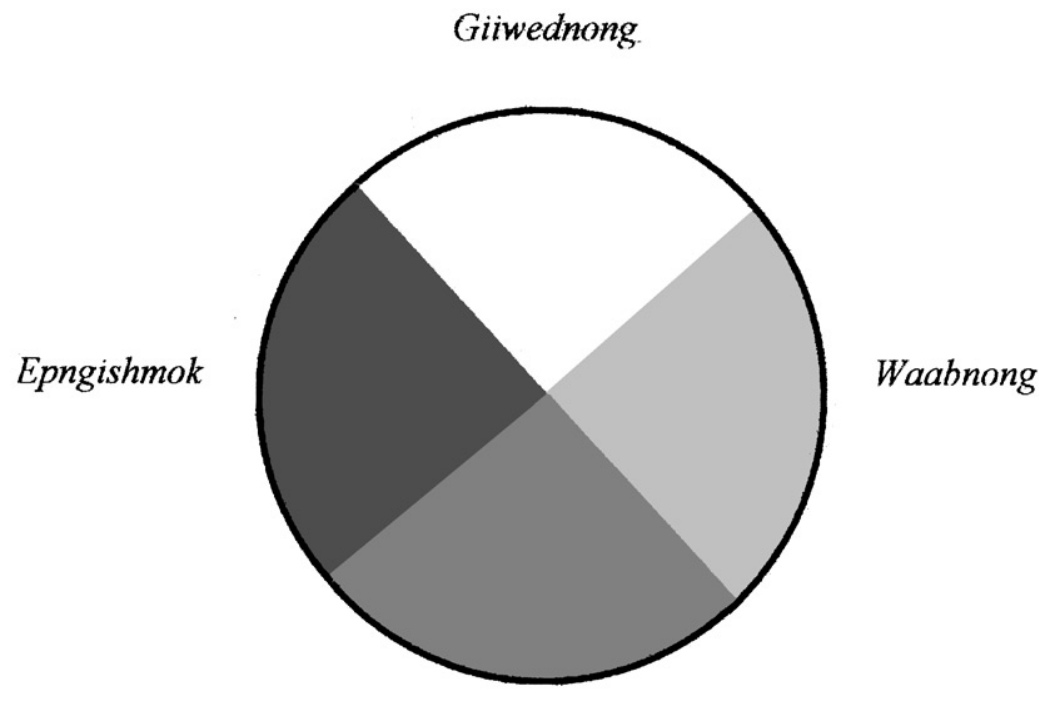

\section{Zhaawnong}

Fig. 1. Anishinabek medicine wheel.

land shapes all aspects of their lives: the cultural, spiritual, emotional, physical and social lives of individuals and communities (see Akiwenzie-Damm, 1996; RCAP, 1996a-c, 1995; Mercredi and Turpel, 1993; Shkilnyk, 1985).

Anishinabek consider the land to be a female entity and a provider of all things necessary to sustain life and as such is referred to as Shkagamik-Kwe (Mother Earth) as is evident in Allan's description of the land: ${ }^{4}$

I believe that we came from the earth-just like everything is alive, potatoes, plants, anything comes alive and flourishes with flowers. The earth provides everything, wild animals, insects. The earth provides for us. The earth provides strength, that's why we call it mother. She provides life...helps us live. Without her we would not live.

Thus, in this paper, the terms 'land' and 'Mother Earth' are used interchangeably as a way of exploring place, identity and health.

When describing Mother Earth, most people referred to her as encompassing the earth in its entirety and contributing to all aspects of everyday life. As one elder, Helen, told me:

Mother Earth is everything that you see. You look everywhere on earth and you see Mother Earth. The

\footnotetext{
${ }^{4}$ Pseudonyms are used to protect the identity of all participants.
}

way you raise your children, the way people do things together, the way we live among our people. She is in everything we do.

The interviews revealed a common theme that is crosscut by age and gender; the land represents more than just the physical or symbolic space in which people carry out their daily activities.

Geographic research has shaped our understandings of the ways in which places, monuments, and landscape features imbue identity at national, regional and local levels. Gillis (1994) draws a link between social memory, monuments and the development of national identities. Places are argued to shape identity or as Gesler states (1991, p. 8) "places influence personal identity" (emphasis added). As such, there is a sense that identity and place are separable from one another. However, the above quote by Helen exemplifies that the relationship Anishinabek have with the land cannot be captured by the simplified notion of being 'close to nature'. The land is not just seen as shaping or influencing identity, but being an actual part of it.

The land simultaneously contributes to physical, emotional, mental and spiritual health in a variety of ways. As evidenced in Allan's quote above, the land is believed to provide all of the resources (e.g., food and medicines) necessary for survival. There is a strong link between food and medicine for Anishinabek. Certain plants, berries, and animals, which are provided by the land, are not only consumed for nutritional reasons but can also be used in the production of 
medicines. Sandra spoke about the importance of traditional medicines:

My mom makes a lot of medicines like with golden seal or fungus from trees or tree roots and barks and different things. If I'm sick with an illness I'll just ask her to go and make me some medicine and she goes out and 10 minutes later she is back with these things and she is making me something. It is pretty funny because I always say we don't have a 24 hour pharmacy ... but I guess in a sense we do.

It is important to recognize that the land represents more than just a physical location of healing. It must be understood as part of an intricate relationship in the everyday lives of Anishinabek between the physical, spiritual, and symbolic realms of Anishinabek identities. In addition, relationships to the land do not just exist solely on the ground but also in the minds of individuals. As Lynda commented, it is not enough to be physically connected to the land, there must also be a spiritual connection:

She (Mother Earth) is something that heals you if you let it. You don't always feel it. You have to be thinking about it. You can't just go out for a walk and feel it. You have to be spiritually connected to feel her.

Spirituality is an important part of health for Anishinabek. However, research conducted within the medical field has shown that, in general, the importance of spirituality for health is poorly understood (Morrison, 1990). When interviewing the traditional healer, he emphasized the importance of traditional medicines, stressing the significance of the spiritual aspects of these medicines for health. He stated that spirituality is an important part of health that cannot be achieved through Western medicine:

Herbal medicines can't be arranged like Western medicine because there is a spiritual component which becomes weaker when it is analyzed. It is difficult for medical professions in the Western world to understand it... Western medicine is the physical, mental, emotional but not the spiritual. I find it's not there. In the Native world everything comes from the heart. That's where it is.

Individuals are connected spiritually to both the Creator and Mother Earth through their medicines and this helps to maintain health. Cedar, sweetgrass, sage and tobacco are considered to be sacred medicines and they are used in a variety of ways to connect with Mother Earth and the Creator. In addition, smudging, which involves the burning of the sacred medicines and the symbolic washing or healing of the body, mind and spirit, is also done by some. Patrick told me that he views smudging as "the fibre optic cable that provides a direct link to the Creator". In addition, Sandra stated that; "Tobacco is your 911 connection to the Creator. ${ }^{5}$ We believe that our prayers get offered up to the Creator through the smoke". In terms of the therapeutic benefits associated with using these medicines, many individuals commented that smudging is healing:

It's just a belief that we are purifying our mind and our body and our spirit. Like when you see people smudging I don't know if you noticed but they rub it on their hair and that's to clean their hair and their minds and stuff. They'll make smoke go to their eyes so that they'll see good things. They'll make the smoke go to their mouth so that they'll say good things and they'll make the smoke go to their ears so that they'll hear good things and to their heart so that there's good things in their heart. Then they'll smudge the rest of their body (Sandra).

The literature on therapeutic landscapes emphasizes the importance of symbols and symbolic landscapes in shaping health (see Kearns and Barnett, 1999; Scarpaci, 1999). James Waldram (1997) has argued that health in Aboriginal populations requires both physical (removal of disease) and symbolic (balance between the individual, society, and the spiritual realm) healing. He goes on to say that symbolic healing is dependent upon "the use, interpretation, negotiation, and manipulation of cultural symbols as central to the process of healing" (Waldram, 1997, p. 71).

One of the most visual cultural symbols found on the land is the sweat lodge. In a sweat lodge, saplings are tied together to construct a dome-like structure. In the middle of the sweat lodge there is pit in which the grandfathers (rocks) are placed. During a sweat lodge ceremony, the inside is made completely dark and water is sprinkled on the grandfathers, which creates heat. Within the sweat lodge individuals come together for praying, drumming and singing.

The function of the sweat lodge is multifaceted: it is used for prayer, to maintain health and for health and social problems, such as, alcoholism and drug addictions (see Grosbsmith and Dam, 1990; Waldram 1993, 1997; Waldram et al., 1995; Hall, 1986). Sweat lodges have also been used successfully within correctional facilities in Canada as noted by Waldram $(1993,1997)$.

While its therapeutic benefits have been noted widely, what is interesting is the deeply rooted symbolism of the sweat lodge. Through prayer, singing, drumming and sweating, the sweat lodge provides one of the most direct spiritual and symbolic links between an individual, Mother Earth and the Creator. The dome-like shape of the sweat lodge is highly symbolic of the relationship

\footnotetext{
${ }^{5}$ 9-1-1 is a North American emergency response for police, fire and ambulance services.
} 
individuals have with the land, in the image of Mother Earth. The healing properties of the sweat lodge were described by a number of individuals. Allan described what the sweat lodge means to him:

One way to get in tune with the earth is to go to a sweat lodge. The lodge represents Mother Earth's belly, her womb. You go into the sweat praying and sweating. It is a cleansing and the whole time you are in there, you are praying. When you crawl out, it is like you are re-born, like a child. You feel so good when you come out of there.

Laws and Radford (1998) argue that by conceptualizing places as social relations and practices, the link between place, identity and health becomes explicit. They assert that places are loci of social relations and practices that operate among different people. These social relations shape both the experience of place and an individual's sense of self, which are both central to health. Obviously, much of the research that examines the link between place, identity and health focuses on social relations among people (see Laws and Radford, 1998; Williams, 1999; Wilton, 1999).

The world-view of Anishinabek, however, involves the existence of other-than-human beings. Therefore it is necessary to examine how relations to spirits serve to maintain health. The belief that the land is alive with spirits lends itself to positive mental and emotional health. Anishinabek believe that all things on earth are alive and contain spirits. As such, the land represents a site within which Anishinabek can relate to other animate beings in their everyday lives. This connection lends itself to positive emotional and mental health. Numerous individuals stated that they communicate with the spirits of rocks and trees when dealing with problems, and/or conflict. It appears that this gives individuals a way of meditating and gaining focus on a situation. While not everyone indicated that they do this, some individuals prefer to communicate with spirits, as opposed to humans. Allan remarked:

It doesn't matter where you go. If I have problems I take a walk in the bush. I talk to the trees and they listen. They take my problems away.

As discussed earlier, the land contributes to physical health by providing individuals with the foods and medicines necessary to be well. Participation in certain activities, such as putting down tobacco, hunting, and harvesting medicines, makes people feel good. When an individual is feeling ill, traditional medicines can be used to alleviate illness. In this sense, both the nutritional properties of food and the healing benefits of medicines are necessary for health. Borrés (1994, p. 6) research on the consumption of seal by the Inuit demonstrates that "feeling good is dependent on eating the animals that are found in nature". It is also necessary to acknowledge the important emotional healing benefits associated with the physical and spiritual aspects of hunting, trapping, fishing and harvesting food and medicines. For example, Patricia described the way these activities make her feel:

I hunt, I camp, I fish and I have always done that and I always feel good when I'm out there in the bush. To me it's almost like a cleansing. I can go out there and I just feel so good, like my mind gets so cleared. I love it.

This statement encapsulates the idea that these activities provide a direct link between Anishinabek and the land, which in turn supports health and healing. Similarly, Patrick described the healing benefits he experiences while working as a medicinal harvester:

I came up with a phrase the other day that describes how I feel, "Harvesting medicine is medicine". I really think about the therapeutic aspect involved in knowing that you are out there being spiritually connected with Mother Earth and what she provides for you. You are picking plants and putting down tobacco, thanking her for what she has given but at the same time you are rejuvenating yourself. You are healing yourself within. You are making yourself feel good.

These quotes demonstrate that the activities in which individuals participate in their everyday lives are important for physical, emotional, mental and spiritual health. Activities such as hunting and harvesting are not only of nutritional benefit, which supports physical health, they also allow individuals to connect spiritually with Mother Earth, the Creator and spirits while being on the land. This is important because it allows individuals to pursue simultaneously physical and spiritual connections to the land that are important for emotional and mental health. This helps to maintain a sense of balance.

It is important to understand that the relationship between the land and health is much more complex than what has been presented. There are other issues that need to be considered. First, men and women have different roles and therefore connect in different ways to the land. Further research is needed to gain insight into the ways that gender shapes the relationship between health and place. Second, much of the research on therapeutic landscapes has focussed on the material and symbolic aspects of place as being positive agents for health. However, themes arose during the analysis of the interviews that suggest that relationships to the land can also influence health in a negative way. Finally, the interviews also suggested that relationships to the land are manifested across different physical and symbolic scales. Scale has always played a pivotal role in 
geographic inquiry. While Gesler (1991) poses the question ' $[\mathrm{O}] \mathrm{n}$ what scale is place encountered?' in his book The Cultural Geography of Health Care, much of the research centered on therapeutic landscapes has overlooked the multiple scales at which these landscapes are experienced (see Wilson, 2000).

Phillips and Rosenberg (2000) argue that research conducted within the Geography of Health tends to be an exercise in 'intellectual imperialism'. That is, much of the research is conducted within English-speaking countries and there exists little room for exploring how theoretical arguments might be applied within the context of developing countries (Phillips and Rosenberg, 2000 , p. 376 emphasis added). Their characterization of intellectual imperialism needs to be extended. We must question if western theoretical arguments should be applied in other settings. Applying such constructs to cultural groups for which they have very little or no meaning could be argued to be another form of intellectual imperialism.

It has been suggested that the scope of therapeutic landscapes be expanded so as to include holistic (Williams, 1998) and indigenous (Madge, 1998) medicine. However, to apply this body of theory uncritically to other cultural groups is an exercise in intellectual imperialism. Therapeutic landscapes tend to be reductionist in their approaches to health and place. To date they have mainly explored discrete sites of healing and extraordinary events. As demonstrated in this paper, the land represents more than just a geographic location or a site of healing. To explore fully First Nations peoples' health, one must recognize the complexity of the interrelationships between health, identity, spirituality, and place that exist in everyday lives.

\section{Conclusions-linking culture, health and place}

The purpose of this paper was to address how therapeutic landscapes shape health in people's everyday lives by incorporating a cultural approach to understanding the link between health and place for Anishinabek living on one reserve in northern Ontario, Canada. In so doing, this paper examined the importance of the land, as place, for Anishinabek health in their everyday lives. In emphasizing the role that therapeutic landscapes play in people's everyday lives, this paper goes beyond most other studies of therapeutic landscapes, which explore the importance of culture (i.e., systems of belief, values and traditions), but emphasize extraordinary landscapes (e.g., well-known religious shrines or spas).

While incorporating culture provides insight into any research project, as Kearns and Dyck (1999) argue, it is not enough to include others within our research. We must acknowledge the significance and validity of other ways of knowing. It is also important to recognize culturally specific dimensions of health and place, which tend to be overlooked within examinations of therapeutic landscapes.

This paper demonstrates how geographic research on the health of First Nations peoples can be improved by including their cultural conceptualizations of health and place. Anishinabek have distinct cultural conceptions of health that emphasize the importance of balance between all aspects of life. The land represents more than just the physical or symbolic spaces in which Anishinabek carry out their daily lives. Individuals have physical, symbolic and spiritual relationships to the land. Physically, individuals connect with the land by putting down tobacco, hunting, trapping, fishing, harvesting food and medicines, and taking part in ceremonies. Symbolically, the land represents the connection Anishinabek have with the land in the image of Mother Earth. Relationships to the land also include a spiritual element in that Anishinabek believe that the land is alive and contains spirits. All of these aspects of relationships to the land are necessary for mno bmaadis.

While much of the current research conducted on therapeutic landscapes is useful, it mainly constitutes western conceptions of health and place. Current research overlooks the complex ways in which the link between health and place is manifested simultaneously in physical, symbolic, spiritual, cultural and neocolonial relationships to the land on a daily basis. Anishinabek have conceptions of place that differ from our own. The land represents more than just a physical or symbolic location of healing. It represents the complex intersection of culture, identity and health as manifested in their daily geographies. To move forward research conducted within the framework of therapeutic landscapes must make room for the exploration of the links between health and place as manifested in the daily lives and geographies of individuals.

\section{Acknowledgements}

Funding for this research was provided by the Social Sciences and Humanities Research Council of Canada and the School of Graduate Studies Queen's University, Kingston, Ontario. The author would like to thank Mark Rosenberg for his valuable insight as well as the feedback provided by anonymous reviewers.

\section{References}

Abel, S., Kearns, R.A., 1991. Birth places: a geographical perspective on planned home birth in New Zealand. Social Science and Medicine 33 (7), 825-834. 
Akiwenzie-Damm, K., 1996. We belong to this land: a view of cultural difference. Journal of Canadian Studies 31 (3), 21-28.

Bell, M., 1999. Rehabilitating Middle England: the integration of ecology, aesthetics and ethics. In: Williams, A. (Ed.), Therapeutic Landscapes: The Dynamic Between Place and Wellness. University Press of America, New York, pp. 15-27.

Benton-Banai, E., 1988. The Mishomis Book: The Voice of the Ojibway. The Red School House, Saint Paul Minnesota.

Bhabha, H., 1994. The Location of Culture. Routledge, New York.

Bopp, J., Bopp, M., Brown, L., Lane, P., 1984. The Sacred Tree. Four Worlds Development, Lethbridge.

Borré, K., 1994. The healing power of the seal: The meaning of Inuit healing practice and belief. Arctic Anthropology 31 (1), 1-15.

Briggs, C.L., 1986. Learning How to Ask: A Sociolinguistic Appraisal of the Role of the Interview in Social Science Research. Cambridge University Press, Cambridge.

Canada, 1997. Catalogue of Diabetes Education Resources for First Nations Peoples. Medical Services Branch, Ottawa.

Dickason, O.P., 1997. Canada's First Nations: A History of Found Peoples from Earliest Times. Oxford University Press, Toronto.

Dyck, L.E., 1996. An analysis of western, feminist and Aboriginal science using the medicine wheel of the Plains Indians. Native Studies Review 11 (20), 89-102.

Frazier, L.Z., Scarpaci, J.L., 1998. Landscapes of state violence and struggle to reclaim community: mental health and human rights in Iquique, Chile. In: Kearns, R.A., Gesler, W.M. (Eds.), Putting Health into Place: Landscape, Identity, and Well-Being. Syracuse University Press, Syracuse, pp. 53-74.

Geores, M.E., 1998. Surviving on metaphor: how "Health = Hot springs" created and sustained a town. In: Kearns, R.A., Gesler, W.M. (Eds.), Putting Health into Place: Landscape, Identity, and Well-Being. Syracuse University Press, Syracuse, pp. 36-52.

Gesler, W.M., 1991. The Cultural Geography of Health Care. University of Pittsburgh Press, Pittsburgh.

Gesler, W.M., 1992. Therapeutic landscapes: Medical issues in light of the new cultural geography. Social Science and Medicine 34 (7), 735-746.

Gesler, W.M., 1993. Therapeutic landscapes: Theory and a case study of Epidauros, Greece. Environment and Planning D: Society and Space 11, 171-189.

Gesler, W.M., 1996. Lourdes: healing in a place of pilgrimage. Health and Place 2 (2), 95-105.

Gesler, W.M., 1998. Bath's reputation as a healing place. In: Kearns, R.A., Gesler, W.M. (Eds.), Putting Health into Place: Landscape, Identity, and Well-Being. Syracuse University Press, Syracuse, pp. 17-35.

Gillis, J.R., 1994. Commemorations: The Politics of National Identity. Princeton University Press, New York.

Grosbsmith, E., Dam, J., 1990. The revolving door: Substance abuse treatment and criminal sanctions for Native American offenders. Journal of Substance Abuse 2, 405-425.

Hall, R., 1986. Alcohol treatment in American Indian populations: An indigenous treatment modality compared with traditional approaches. Annals of the New York Academy of Sciences 472, 168-178.

Hooks, B., 1990. Yearning: Race, Gender, and Cultural Politics. Between the Lines, Toronto.

Johnson, J.C., 1990. Selecting Ethnographic Informants (Qualitative Research Methods Series No 22). Sage Publications, California

Jones, K., Moon, G., 1993. Medical geography: Taking space seriously. Progress in Human Geography 17 (4), $515-524$.

Kearns, R.A., Dyck, I., 1995. Transforming the relations of research: Towards culturally safe geographies of health and healing. Health and Place 1 (3), 137-147.

Kearns, R.A., Barnett, R., 1999. Auckland's starship enterprise: placing metaphor in a children's hospital. In: Williams, A. (Ed.), Therapeutic Landscapes: The Dynamic Between Place and Wellness. University Press of America, New York, pp. 169-199.

Kearns, R.A., Gesler, W.M., 1999. Introduction. In: Kearns, R.A., Gesler, W.M. (Eds.), Putting Health into Place: Landscape, Identity, and Well-Being. Syracuse University Press, Syracuse, pp. 1-16.

Kearns, R.A., Joseph, A.E., 1993. Space in its place: Developing the link in medical geography. Social Science and Medicine 37 (6), 711-717.

Kirby, S., McKenna, K., 1989. Experience Research Social Change: Methods from the Margins. Garamond Press, Toronto.

Laws, G., Radford, J., 1998. Place, identity and disability: narratives of intellectually disabled people in Toronto. In: Kearns, R.A., Gesler, W.M. (Eds.), Putting Health into Place: Landscape, Identity, and Well-Being. Syracuse University Press, Syracuse, pp. 77-101.

Macaulay, A.C., Hanusaik, N., Beauvais, J.E., 1989. Breastfeeding in the Mohawk community of Kahnawake: revisited and redefined. Canadian Journal of Public Health 80, 177-181.

Madge, C., 1998. Therapeutic landscapes of the Jola, The Gambia, West Africa. Health and Place 4 (4), 293-311.

Malloch, L., 1989. Indian medicine, Indian health: study between red and white medicine. Canadian Women Studies $10(2-3), 105-112$.

McLeod-Shabogesic, P., 1998. What is an elder? Anishinabek News 10 (11), 31

Medicine, B., 1983. The elders tell me. In: MacCaskill, D., Hebert, Y. (Eds.), Native Education, Vol. 2. University of Toronto Press, Toronto.

Mercredi, O., Turpel, M.E., 1993. In the Rapids: Navigating the Future of First Nations. Toronto: Penguin Books, Canada.

Morrison, R., 1990. Spiritual health care and the nurse. Nursing Standard 5, 34-35.

Palka, E.J., 1999. Accessible wilderness as a therapeutic landscape: experiencing the nature of Denali National Park, Alaska. In: Williams, A. (Ed.), Therapeutic Landscapes: The Dynamic Between Place and Wellness. University Press of America, New York, pp. 29-51.

Pearson, M., 1988. Medical geography: genderless and colour blind? Contemporary Issues in Geography and Education. Journal of the Association for Curriculum Development in Geography 3, 9-17. 
Phillips, D., Rosenberg, M., 2000. Researching the geography of health and health care: connecting with the third world. GeoJournal 50, 369-378.

Rathwell, T., Phillips, D.R., 1986. Health, Race and Ethnicity. Croom Helm, London.

RCAP, 1996a. Restructuring the Relationship, Part 1, Vol. 2. Ministry of Supply and Services, Ottawa.

RCAP, 1996b. Restructuring the Relationship, Part 2, Vol. 2. Ministry of Supply and Services, Ottawa.

RCAP, 1996c. Perspectives and Realities, Vol. 4. Ministry of Supply and Services, Ottawa.

RCAP, 1996d. Gathering Strength, Vol. 3. Ministry of Supply and Services, Ottawa.

Rosenberg, M., 1998. Medical or health geography? Populations, peoples and places. International Journal of Population Geography 4, 211-226.

Royal Commission on Aboriginal Peoples (RCAP), 1995. Treaty Making in the Spirit of Co-Existence: An Alternative to Extinguishment. Ministry of Supply and Services, Ottawa.

Said, E., 1993. Culture and Imperialism. Knopf, New York.

Scarpaci, J., 1999. Healing landscapes: revolution and health care in post-socialist Havana. In: Williams, A. (Ed.), Therapeutic Landscapes: The Dynamic Between Place and Wellness. Oxford University Press, New York, pp. 201-220.

Shkilnyk, A.M., 1985. A Poison Stronger Than Love: The Destruction of an Ojibwa Community. Yale University Press, New Haven.

Spielmann, R., 1998. 'You're So Fat': Exploring Ojibwe Discourse. University of Toronto Press, Toronto.

Spivak, G., 1988. Can the subaltern speak? In: Nelson, C., Grossberg, L. (Eds.), Marxism and the Interpreta- tion of Culture. University of Illinois Press, Urbana, IL.

Stiegelbauer, S.M., 1996. What is an elder? What do elders do?: First Nations elders as teachers in culture-based urban organizations. The Canadian Journal of Native Studies 16 (1), 37-66.

Valentine, L.P., 1995. Making it their Own: Severn Ojibwe Communicative Practices. University of Toronto Press, Toronto.

Waldram, J.B., 1993. Aboriginal spirituality in corrections: a Canadian case study in religion and therapy. American Indian Quarterly 18 (2), 197-215.

Waldram, J.B., 1997. The Way of the Pipe: Aboriginal Spirituality and Symbolic Healing in Canadian Prisons. Broadview Press, Peterborough, Ontario.

Waldram, J.B., Herring, D.A., Young, T.K., 1995. Aboriginal Health in Canada: Historical, Cultural, and Epidemiological Perspectives. University of Toronto Press, Toronto.

Williams, A., 1998. Therapeutic landscapes in holistic medicine. Social Science and Medicine 46 (9), 1193-1203.

Williams, A., 1999. Place identity and therapeutic landscapes: the case of home workers in a medically underserviced area. In: Williams, A. (Ed.), Therapeutic Landscapes: The Dynamic Between Place and Wellness. University Press of America, New York, pp. 71-96.

Wilson, K., 2000. The Role of Mother Earth in Shaping the Health of Anishinabek: A Geographical Exploration of Culture, Health and Place. Unpublished $\mathrm{PhD}$ dissertation. Kingston, Ontario: Queen's University.

Wilton, R.D., 1999. Qualitative health research: negotiating life with HIV/AIDS. The Professional Geographer 51 (2), 296-306. 